\title{
The association between dyslipidemia and anthropometric indicators in black and white adolescents residing in Tlokwe Municipality, North-West Province, South Africa: the PAHL study
}

\author{
Ramoteme L Mamabolo ${ }^{1,2}$, Martinique Sparks ${ }^{3}$, Sarah J Moss ${ }^{3}$, Makama A Monyeki ${ }^{3}$
}

1. Department of Nutrition, School of Health Sciences, University of Venda, Thohoyandou, South Africa

2. Centre of Excellence for Nutrition, Faculty of Health Sciences, North-West University (Potchefstroom Campus), Potchefstroom, South Africa

3. School of Biokinetics, Recreation and Sport Science, Faculty of Health Sciences, North-West University (Potchefstroom Campus), Potchefstroom, South Africa

\begin{abstract}
Background: The dyslipidemia associated with excess weight is a risk for cardiovascular disease. Worldwide and in South Africa adolescent obesity has been reported.

Objectives: To determine the association between dyslipidemia and anthropometric indices in black and white adolescents. Methods: The study involved 129 black and 69 white adolescents aged 12 to 16 years. Data collected included height, weight, waist circumference (WC) and skinfolds, blood pressure and blood for glucose, insulin, total cholesterol (TC), low density lipoprotein (LDL), high density lipoprotein (HDL), triglycerides (Trig) and C - reactive protein (CRP).

Results: WC correlated negatively with HDL in both blacks $(\mathrm{p}=0.042)$ and whites $(\mathrm{p}=0.008)$ and in whites it correlated positively with LDL $(\mathrm{p}=0.006)$; TC/HDL $(\mathrm{p}=<0.001)$ and LDL/HDL ratio $(\mathrm{p}<0.0001)$. WC/Hgt correlated negatively with HDL $(\mathrm{p}=0.028)$ and positively with LDL/HDL $(\mathrm{p}=0.026$ and $\mathrm{p}<0.0001)$ in both races. In whites positive correlations were between WC/Hgt and TC ( $\mathrm{p}=0.049)$; LDL $(\mathrm{p}=0.003)$ and TC/HDL $(\mathrm{p}<0.0001)$. BAZ correlated positively with TC/HDL ratio $(\mathrm{p}=0.004)$ and LDL/HDL ratio $(\mathrm{p}=0.002)$. The most common abnormalities were HDL and LDL.

Conclusion: Whites exhibited more associations between dyslipidemia and anthropometric indicators as compared to Blacks, suggesting that there might be differences in the lipid metabolism or even susceptibility to risk factors in adolescents.
\end{abstract}

Key words: dyslipidemia, anthropometry, adolescents

DOI: http://dx.doi.org/10.4314/ahs.v14i4.23

\section{Introduction}

There are several risk factors for coronary heart diseases, which can act independently or together. Among the most common are arterial hypertension, smoking, a sedentary lifestyle, diabetes, obesity, dyslipidemias, and a positive familial history of cardiovascular disease (CVD). The precocity of these factors signals the need to develop prevention and intervention strategies in pediatric populations.

Atherosclerosis coronary heart disease (CHD) has multifactorial causes. Studies have established that dy-

\footnotetext{
Corresponding author:

Ramoteme L Mamabolo, University of Venda, Private Bag X 5050, Thohoyandou, 0950.

E-mail ramoteme.mamabolo@univen.ac.za.

Tel: +27 159628386 .

Fax: +2715962 4749.
}

slipidemia plays an important role in its development and progression. Even though clinical CHD only occurs in later life it is known that atherosclerosis may already present itself in young adults ${ }^{1}$. It has also been observed that conditions related to altered lipid levels such as unhealthy dietary habits, tobacco smoking and physical inactivity are acquired during childhood and adolescence $^{2}$. Moreover, obesity, dyslipidemia and hypertension in adolescence have been reported to track into adulthood ${ }^{3}$. Other studies have shown that differences in lipid levels among cultures and ethnic groups appear early in childhood ${ }^{3}$.

Waist circumference (WC) and waist-to-height ratio (WHtR) during childhood are predictors of the development of risk factors for CVD. Visceral adiposity has a strong impact on CVD due to its association with dyslipidemias, arterial hypertension, insulin resistance and diabetes. High plasma triglycerides (TG) and low concentrations of high-density lipoprotein cholesterol 
(HDL- C) are among the alterations observed in the Study sample

lipid profile that are primarily related to central fat distribution ${ }^{4}$.

Childhood obesity has been on the increase in the past decades $^{5}$ and furthermore, it has been shown to be a predictor of increased mortality owing primarily to an increased risk of $\mathrm{CVD}^{6}$. In addition, the prevalence of individuals with normal body weight who display one or more obesity related morbidity such as type 2 diabetes and high blood pressure is increasing 7,8 . There is substantial evidence that the association between obesity and CVD is due to adverse CVD risk factor profile that is seen in obese adults. These include type 2 diabetes, hypertension and dyslipidemia, ${ }^{90}$. To date it is known that all these are emerging in children and adolescents 11,12 .

Studies have shown that detection of altered lipid levels in adolescents especially raised serum levels of total cholesterol (TC) and LDL-C accompanied by low HDL-C can be useful in initiating measures for the prevention of atherosclerotic diseases and reduction of mortality rates ${ }^{11,12,13}$. The metabolic and physiological changes in the lipid profile of adolescents were found to be more pronounced in males than females due to differences in hormonal changes accompanying puberty ${ }^{14}$.

The dyslipidemia associated with excess weight is a risk for cardiovascular disease. In South African adolescents obesity has been reported ${ }^{15}$ and as such the aim of this study was to determine the association between dyslipidemia and anthropometric indices in black and white adolescents.

\section{Methods}

Study area

This study was conducted in Tlokwe Municipality (previously known as Potchefstroom Municipality) of the Dr Kenneth Kaunda District Municipality in the Nort West Province, South Africa. Tlokwe Municipality is located between $26^{\circ} 43^{\prime} 0^{\prime \prime}$ South and $27^{\circ} 6^{\prime} 0^{\prime \prime}$ Eas and longitudes $27,1000\left(276^{\circ} 0.000^{\prime \prime} \mathrm{E}\right)$. The municipality encompasses several neighboring settlements with a population of 128,357 in a density of $48 \mathrm{~km}^{2}$, according to the 2007 community survey. The area is primarily inhabited by Black Africans ( $70 \%$ ), $27.0 \%$ White Africans, 3.0\% Colored and 0.4\% Asians (Stats SA; 2007). The major languages spoken in the area are Setswana, Afrikaans and English. The seat of the local municipality is Potchefstroom.
Data on a total of 198 adolescents (129 Blacks and 69 Whites) from six schools out of the eight school which were purposefully recruited within the Tlokwe municipality with four from Ikageng Township (that mainly consists of people with low socio-economic background) and two in Potchefstroom town (that mainly consists of people with high socio-economic background) participated in the study. This study is part of a five year observational multidisciplinary longitudinal study on Physical Activity and Health Longitudinal Study (PAHLS) that started in 2010. The study conveniently selected grade 8 pupils for baseline so as to make the five-year follow-up feasible; additionally, given the fact that schools are good grounding to conduct research studies which are longitudinal in nature for its logistics. The group of pupils studied may not be considered to be representative of the adolescents' population of either Tlokwe municipality or South Africa in general. Its goal was to describe the development of physical activity and determinants of health risk factors in adolescents attending high schools within Tlokwe municipality areas of the North West Province of South Africa since such information in this region is lacking in the literature, as such information may be of grateful in addressing the abnormalities of health risk factors.

\section{Anthropometric measurements}

Anthropometric measurements of height, weight and skinfolds were measured by Level 2 Criteria anthropometrists according to the standard procedures described by the International Society for the advancement of Kinanthropometry: ISAK ${ }^{16}$. Height was measured by the use of stadiometer to the nearest 0.1 centimeter (cm) with participants in a bare feet standing upright position with the head in the Frankfort plane. Weight was measured to the nearest 0.1 kilogram $(\mathrm{kg})$ with an electronic scale with the subject wearing minimal clothing. The triceps and subscapular skinfolds were measured to the nearest $0.2 \mathrm{~mm}$ with a Harpenden (British Indicators, UK) skinfold caliper and the average of two measurements were used. The waist circumference (WC) was measured, to the nearest $0.1 \mathrm{~cm}$ with a $7-\mathrm{mm}$ wide flexible steel tape (Lufkin, Cooper Tools, Apex, $\mathrm{NC}$ ), at the midpoint between the lower rib margin and the iliac crest. The hips were measured to the nearest $0.1 \mathrm{~cm}$ at maximum extension of the buttocks. Waist to-hip ratio (WHR) was calculated from waist and hip circumferences. Body mass index (BMI) as a measure of body composition was calculated as body mass/ stature $^{2}\left(\mathrm{~kg} / \mathrm{m}^{2}\right)$. Subsequently, height-for age $\mathrm{z}$-score (HAZ), weight-for-height z-score (WHZ), weight-forage $z$ - score (WAZ) and as well as BMI $z$-score (BAZ) were classified according to WHO Multicentre study references ${ }^{17}$.

\section{Blood analysis}

Participants were requested to fast for 12 hours before blood samples were taken in the morning. Professional nurses took venous blood from the cephalic vein for the preparation of serum. The tubes were kept for approximately 30 min to coagulate and then centrifuged for 15 $\min$ at $2000 \mathrm{~g}$ for the serum. The serum was divided into aliquots and stored at $-84^{\circ} \mathrm{C}$ until analysed at an accredited laboratory (Ampath Laboratories, Pretoria, South Africa). Serum was used for the analyses of total cholesterol (TC), low density lipoproteins (LDL), high density lipoproteins (HDL), triglycerides (Trig) and Creactive proteins CRP. Serum TC, LDL, HDL, Trig, was measured with a Vitros DT60 II Chemistry Analyse (Ortho-Clinical Diagnostics, Rochester, NY, USA) with Vitros reagents and controls.Serum high-sensitivity $\mathrm{C}$ reactive protein was determined by rate turbidimetry with a High Sensitivity C-Reactive Protein kit (CRPH, IMMAGE, Immunochemistry Systems, Fullerton, (CA, USA) with control serum as an external standard.

\section{Diagnosis of abnormal lipid parameters}

Abnormal lipid parameters were defined by using the following criteria: HDL-C: $<1.2 \mathrm{mmol} / \mathrm{LLDL}:>2.5$ mmol/LTC: $>2.3 \mathrm{mmol} / \mathrm{L}$ LDL/HDL ratio: $<2.20$ TC/HDL ratio: $<3.5$

\section{Ethical consideration}

This study was approved by the ethics committee of Triglyceride and glucose levels were lower in blacks North-West University (Potchefstroom campus) and before adjusting for gender as were TC/HDL ratio approved by both the North-West Province Depart- and LDL/TC ratio with lower values recorded in Black ment of Health and Social Welfare Research commit- adolescents but these differences were not there after tee and Department of Education. Written informed adjusting for gender differences (Table 1). 
Table 1: Anthropometric and Biochemical variables of Black and White Adolescents residing in Tlokwe municipality (medians and IQ ranges)

$\begin{array}{llllcc}\text { Variable } & \text { Total (198) } & \text { Africans (n=129) } & \text { Whites (n=69) } & \text { p-Value } & \text { p-Value* } \\ & & & & & \\ \text { Age (years) } & 14.89(0.82) & 14.88(0.94) & 14.90(0.75) & 0.581 & 0.947 \\ \text { Weight (kg) } & 54.0(14.0) & 51.0(14) & 61.0(16.0) & <0.0001 & <0.0001 \\ \text { Height (m) } & 1.61(0.13) & 1.58(11.0) & 1.67(11.0) & <0.0001 & <0.0001 \\ \text { BMI (kg/m2) } & 20.28(4.75) & 19.82(4.49) & 21.394 .85) & 0.004 & <0.0001 \\ \text { BAZ } & 0.23(1.62) & 0.10(1.50) & 0.53(1.35) & 0.010 & 0.014 \\ \text { TSF + SSF } & 24.10(15.45) & 23.0(15.30) & 26.0(16.90) & 0.451 & 0.053 \\ \text { SSF/TSF ratio } & 0.82(0.32) & 0.82(0.34) & 0.81(0.29) & 0.499 & 0.061 \\ \text { SST ratio } & 0.07(0.05) & 0.07(0.05) & 0.07(0.05) & 0.408 & 0.028 \\ \text { WC (cm) } & 67.5(8.48) & 65.50(7.90) & 70.35(8.60) & <0.0001 & <0.0001 \\ \text { HC (cm) } & 89.40(13.2) & 86.85(12.50) & 92.65(12.30) & <0.0001 & 0.482 \\ \text { WHR } & 0.75(0.08) & 0.75(0.08) & 0.77(0.08) & 0.184 & 0.537 \\ \text { WC/Hgt ratio } & 0.42(0.05) & 0.41(0.05) & 0.42(0.05) & 0.420 & 0.320 \\ \text { CRP (mg/L) } & 2.0(1.0) & 2.0(1.0) & 2.0(1.0) & 0.289 & 0.495 \\ \text { TC (mmol/L) } & 4.0(1.2) & 3.80(1.10) & 4.30(1.30) & <0.0001 & 0.008 \\ \text { Trig (mmol/L) } 0.7(0.4) & 0.60(0.30) & 0.80(0.60) & <0.0001 & 0.206 \\ \text { HDL (mmol/L) } 1.30(0.40) & 1.30(0.40) & 1.30(0.30) & 0.273 & 0.207 \\ \text { LDL (mmol/L) 2.40(1.0) } & 2.20(0.80) & 2.80(0.70) & <0.0001 & 0.002 \\ \text { TC/HDL ratio } 3.17(1.04) & 3.06(0.93) & 3.46(1.0) & <0.0001 & 0.306 \\ \text { LDL/HDL ratio1.92(0.92) } & 1.75(0.79) & 2.22(0.89) & <0.0001 & 0.088 \\ \text { *Adiusted for gender } & & & & \end{array}$

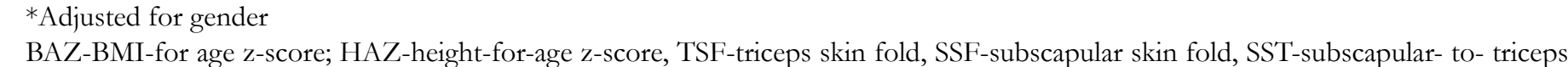
BAZ-BMI-for age z-score; HAZ-height-for-age z-score, TSF-triceps skin fold, SSF-subscapular skin fold, SST-subscapular- to- triceps,
WC-waist circumference, HC-hip circumference, WC/Hgt- waist circumference-to-height, CRP-C-reactive protein, TC- Total cholesterol, Trig-triglycerides, HDL- High density lipoprotein, LDL-low density lipoprotein

Having looked at the measured lipid parameters it ment and this was even stronger with $\mathrm{LDL}(\mathrm{r}=0.426$; was found that the most common abnormalities were $\mathrm{r}=0.011)$ and $\mathrm{LDL} / \mathrm{HDL}$ ratio $(\mathrm{r}=0.601 ; \mathrm{p}<0.0001)$ HDL $92(46.5 \%)[57(44.2 \%)$ Africans and $35(50.7 \%)$ after adjusting for gender. BAZ correlated positively Whites $(\mathrm{X} 2=0.847 ; \mathrm{p}=0.245)$ ]; LDL $83(41.9 \%)(24$ with all measured lipid parameters in both races except (31\%) Africans and $43(62.3 \%)$ Whites $(X 2=4.732 ; \mathrm{p}=$ with HDL with which it was negatively correlated but 0.025)]. TC abnormalities were only observed in Afri- after adjusting for gender it correlated negatively with cans $126(97.5 \%)$. With regard to ratios the most com- TC, LDL and HDL in Black adolescents and only posimon abnormalities were LDL/HDL ratio $135(68.2 \%)$ tively with LDL/HDL ratio in Whites.

[101 (78.3\%) Blacks and $34(49.3 \%)$ Whites (X2= 2.660;

$\mathrm{p}=0.080)]$ and TC/HDL ratio $133(67.2 \%)[98(76 \%)$ Waist circumference-to-height ratio showed positive Blacks and $35(50.7 \%)$ Whites $(\mathrm{X} 2=1.491 ; \mathrm{p}=0.160)] \quad$ correlations with all lipid parameters except with HDI which it was negatively correlated with in both races. Tables 2 and 3 show crude correlation coefficients in After adjusting for gender differences in Black adoles-
black and white adolescents respectively between meas- cents the correlations were still maintained while in black and white adolescents respectively between meas-
ured lipid parameters and anthropometric indices and Whites it remained with LDL, HDL and LDL/HDL after adjusting for gender differences. In Black adoles- ratio. WHR in Blacks was positively correlated with cents BMI showed a negative correlation with TC and Trig ( $r=0.250 ; \quad \mathrm{p}=0.004) ; \mathrm{TC} / \mathrm{HDL}$ ratio $\quad(\mathrm{r}=0.283$; HDL only after adjusting for gender while in Whites $\mathrm{p}=0.001)$ and LDL/HDL ratio $(\mathrm{r}=0.271 ; \mathrm{p}=0.002)$ there was a positive correlation with LDL $(\mathrm{r}=0.293 ; \quad$ and negatively with $\mathrm{HDL}(\mathrm{r}=-0.399 ; \mathrm{p}<0.0001)$ after ad$\mathrm{p}=0.015)$, TC/HDL ratio $(\mathrm{r}=0.412 ; \mathrm{p}<0.0001)$ and justing for gender the remaining associations were with LDL/HDL ratio $(r=0.431 ; \mathrm{p}<0.0001)$ before adjust- TC/HDL ratio $(\mathrm{r}=0.333 ; \mathrm{p}=0.025)$ and $\mathrm{HDL}(\mathrm{r}=-0.353$ $\mathrm{p}=0.017)$. WC was negatively associated with HDL in black adolescents $(\mathrm{r}=0.179 ; \mathrm{p}=0.042)$ and this was even ratio $(\mathrm{r}=478 ; \mathrm{p}<0.0001)$ and negatively with HDL $(-$ stronger after adjusting for gender differences $(r=-0.316 ; \mathrm{p}=0.008)$. After adjusting for gender differ$0.442 ; \mathrm{p}=0.002$ ), furthermore, after taking the gender ences all the correlations remained except with HDL differences into consideration it correlated positively and further WC showed a positive correlation with TC with LDL/HDL ratio. In Whites on the contrary WC $\quad(r=0.360 ; p=0.034)$. Skinfolds indices showed varied aswas positively correlated with LDL $(r=0.483 ; \mathrm{p}=0.003)$, sociations with the lipid parameters in both races ( $\mathrm{Ta}-$ TC/HDL ratio $(r=0.442 ; \mathrm{p}<0.0001)$ and $\mathrm{LDL} / \mathrm{HDL}$ bles 2 and 3).

Table 2: Spearman's correlation coefficients in Black adolescents and adjusted for gender ( $\mathrm{n}=129)$

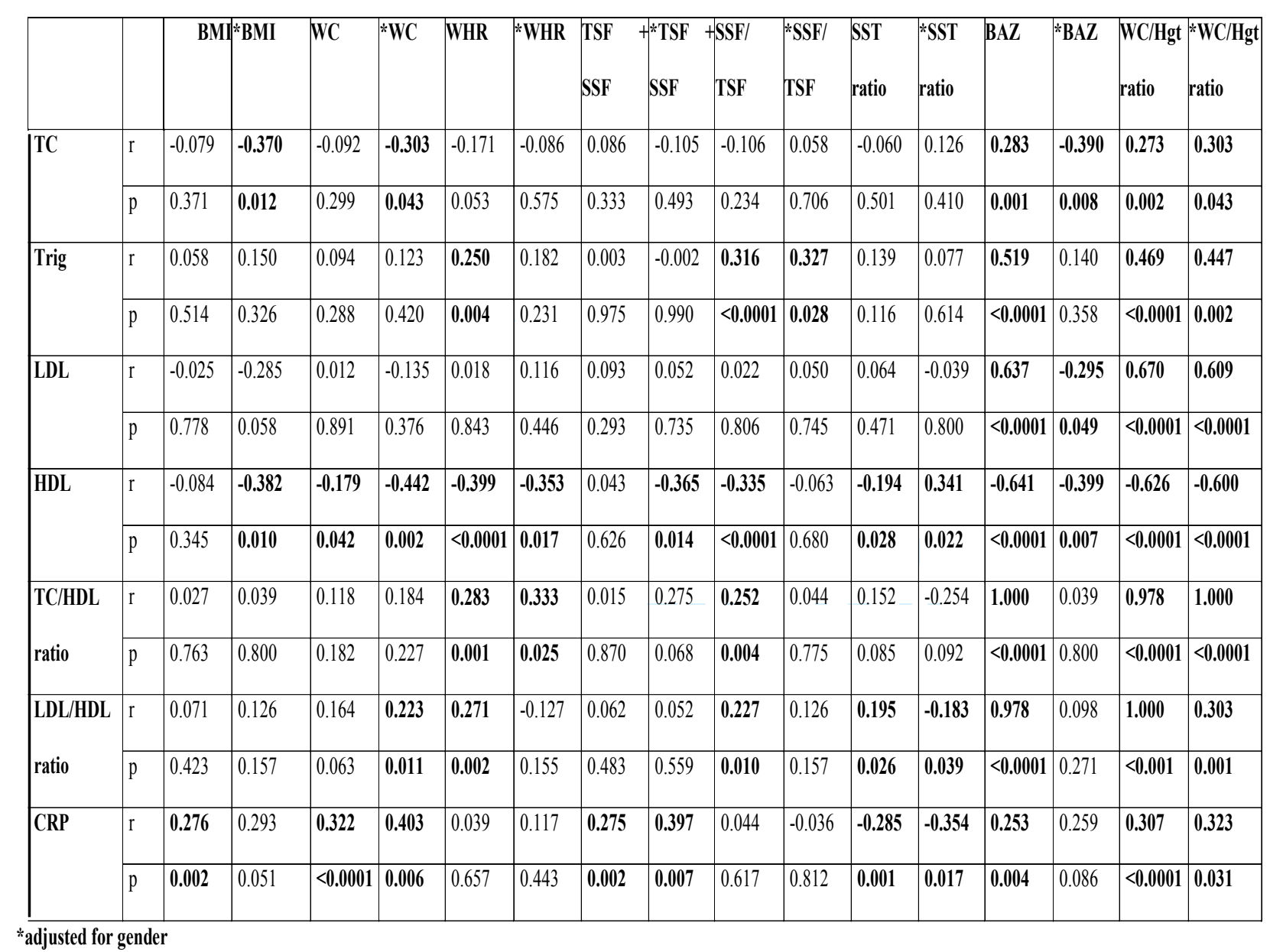

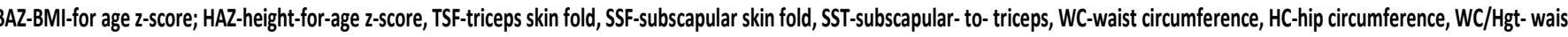
circumference-to-height, CRP.-Creactive protein, TC-Total cholesterol, Trig.trigilycerides, HDL- High density lipoprotein, LDL-Oow density lipoprotein 


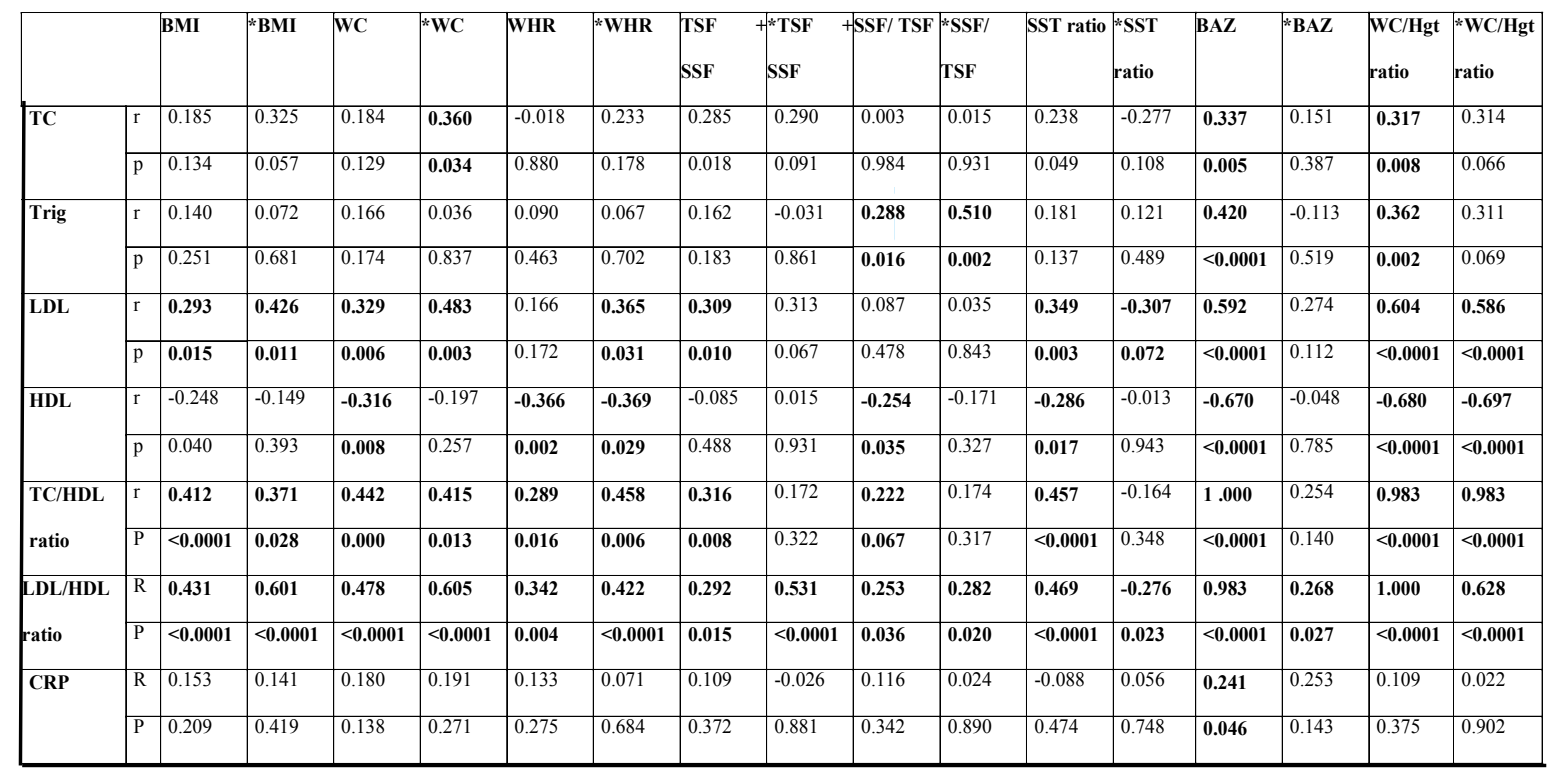

The predictions of skinfolds indices were inconsistent among the indices in both races (Table 4).

Table 4: Linear regression models for assessing the association between anthropometric indices and dyslipidemia in black and whit

$$
\text { adolescents }
$$

\begin{tabular}{|c|c|c|c|c|c|c|c|c|c|}
\hline \multicolumn{2}{|l|}{ Total $(\mathrm{n}=198)$} & & & \multicolumn{3}{|l|}{ Africans ( $(\mathbf{n}=129)$} & \multicolumn{3}{|l|}{\begin{tabular}{|l} 
Whites $(\mathrm{n}=69)$ \\
\end{tabular}} \\
\hline $\begin{array}{l}\begin{array}{l}\text { Dependent } \\
\text { variables }\end{array} \\
\text { a }\end{array}$ & \begin{tabular}{|l}
$\mid \begin{array}{l}\text { Independent } \\
\text { variables }\end{array}$ \\
at
\end{tabular} & $\beta$ & p-value & $\begin{array}{l}\text { Independent } \\
\text { variables }\end{array}$ & B & p-value & $\begin{array}{l}\text { Independent } \\
\text { varizhbles }\end{array}$ & $\beta$ & p-value \\
\hline & $\begin{array}{l}\text { Constant } \\
\text { SSS ratio } \\
\text { BAZ }\end{array}$ & $\begin{array}{l}3.677 \\
0.252 \\
-1.191 \\
0.295\end{array}$ & $\begin{array}{l}x^{0.0001} \\
0.0003 \\
0.027\end{array}$ & \begin{tabular}{|l} 
Constant \\
WC \\
TSF+ SSF
\end{tabular} & $\begin{array}{l}4.881 \\
-0.0148 \\
0.185\end{array}$ & $\begin{array}{l}<0.0001 \\
0.095 \\
0.037\end{array}$ & $\begin{array}{l}\text { Constant } \\
\text { WRR } \\
\text { WC/Hgt ratio }\end{array}$ & $\begin{array}{l}5.390 \\
-0.283 \\
0.422\end{array}$ & $\begin{array}{l}{\left[\begin{array}{l}0.002 \\
0.041 \\
0.003\end{array}\right.} \\
0.003\end{array}$ \\
\hline $\mathrm{R}=0.371, \mathrm{R}^{2}=$ & $0.0 .124, \mathrm{SEE}=0.85$ & $\frac{1}{3,0.030 .000}$ & & $\mathrm{R}=0.219, \mathrm{R}^{2}=0.033$ & SEE $=0.80$ & $p=0.045$ & $\mathrm{R}=0.362, \mathrm{R}^{2}=0$ & $05, \mathrm{SEE}=0.908$ & , \\
\hline Trig & \begin{tabular}{|l|} 
Constant \\
SSATS ratio \\
BAZ Fat \\
WCHgr ratio
\end{tabular} & 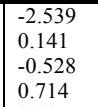 & 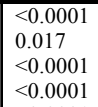 & \begin{tabular}{|l|} 
Constant \\
SSF/TSF \\
WC/Hgt ratio
\end{tabular} & $\begin{array}{l}-0.027 \\
0.236 \\
0.148\end{array}$ & \begin{tabular}{|l|l}
0.920 \\
0.009 \\
0.092
\end{tabular} & 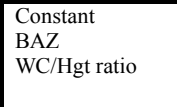 & \begin{tabular}{|l|}
-2.828 \\
-0.568 \\
0.887
\end{tabular} & $\begin{array}{l}<<.0001 \\
<<0.0001 \\
<0.0001\end{array}$ \\
\hline$R=0.618, \mathrm{I}$ & $0.369, \mathrm{SEE}=0.36$ & $\frac{10.01000}{9, p<0.000}$ & & $\mathrm{R}=0.306, \mathrm{R}^{2}=0.07$ & SEE $=0.3$. & , & $R=0.757, R^{2}=$ & 561, SEE $=0.39$ & $\frac{p<0.0001}{p-p}$ \\
\hline LDL & $\begin{array}{l}\text { Constant } \\
\text { WHR } \\
\text { WSF +SSF } \\
\text { BAZ } \\
\text { WC/Hgt ratio }\end{array}$ & $\begin{array}{l}-0.411 \\
-0.117 \\
0.112 \\
0.01174 \\
-0.320\end{array}$ & $\begin{array}{l}0.492 \\
0.047 \\
0.082 \\
0.058 \\
<0.0001\end{array}$ & \begin{tabular}{|l|} 
Constant \\
WHR \\
TSF + SSF \\
BAZ \\
WC/Hgt ratio
\end{tabular} & $\begin{array}{l}0.449 \\
-0.178 \\
0.167 \\
-0.283 \\
-0.314\end{array}$ & $\begin{array}{l}0.578 \\
0.039 \\
0.034 \\
0.058 \\
0.035 \\
0.035\end{array}$ & \begin{tabular}{|l|}
$\begin{array}{l}\text { Constant } \\
\text { WC/Hgt ratio }\end{array}$ \\
\end{tabular} & {$\left[\begin{array}{l}{[.401} \\
0.383\end{array}\right.$} & {$\left[\begin{array}{l}.0 .577 \\
0.001\end{array}\right.$} \\
\hline $\mathrm{R}=0.480, \mathrm{R}^{2}=$ & 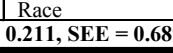 & $\frac{1.084 .01}{9, p<0.000}$ & & $\mathrm{R}=0.311, \mathrm{R}^{2}=0.068$ & SEE $=0.63$ & $p=0.013$ & $\mathrm{R}=0.383, \mathrm{R}^{2}=0$ & 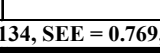 &.$=0.001$ \\
\hline HDL & \begin{tabular}{|l|} 
Constant \\
SSFFTSF \\
WCIH ratio \\
\end{tabular} & \begin{tabular}{|l}
2.230 \\
-0.148 \\
-0.252 \\
-0.252
\end{tabular} & $\begin{array}{l}x^{20.0001} \\
0.03601 \\
<0.0001\end{array}$ & \begin{tabular}{|l|} 
Constant \\
SST ratio \\
WC/Hgt ratio
\end{tabular} & \begin{tabular}{|l|l|}
2.743 \\
-0.0306 \\
-0.386
\end{tabular} & $\begin{array}{l}\qquad \begin{array}{l}0.0001 \\
0.003 \\
0.00001\end{array} \\
<0.0001\end{array}$ & \begin{tabular}{|l|} 
Constant \\
SSS ratio \\
WC/Hgt ratio
\end{tabular} & \begin{tabular}{|l|l|}
2.654 \\
-0.336 \\
-0.569 \\
\end{tabular} & \begin{tabular}{|l}
$<0.0001$ \\
0.014 \\
$<0.0001$
\end{tabular} \\
\hline$R=0.419, R^{2}=$ & 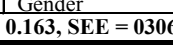 & $\frac{10.24901}{p<1.001}$ & & $\mathrm{R}=0.334, \mathrm{R}^{2}=0.098$ & $\mathrm{SEE}=343$, & & $\mathrm{R}=\mathbf{0 . 4 6 7 , \mathrm { R } ^ { 2 } = \mathbf { 0 }}$ & $194, \mathrm{SEE}=250, \underline{ }$ & $\frac{10.0001}{<1}$ \\
\hline \begin{tabular}{|l|} 
TC/HDL \\
ratio
\end{tabular} & \begin{tabular}{|l|} 
Constant \\
BAC \\
WChg ratio \\
Gender
\end{tabular} & $\begin{array}{l}-2.568 \\
-0.564 \\
0.0663 \\
0.130\end{array}$ & 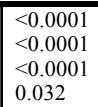 & \begin{tabular}{|l} 
Constath \\
SSATF ratio \\
BAZ \\
WCHgt ratio
\end{tabular} & \begin{tabular}{|l|l|}
-1.294 \\
0.0443 \\
-0.457 \\
0.067
\end{tabular} & $\begin{array}{l}\mid \begin{array}{l}0.198 \\
0.096 \\
0.0002 \\
0.0001\end{array} \\
0.0001\end{array}$ & \begin{tabular}{|l|}
$\begin{array}{l}\text { Constant } \\
\text { WC/Hgt tratio }\end{array}$ \\
\end{tabular} & \begin{tabular}{|l|l|}
-1.347 \\
0.654
\end{tabular} & 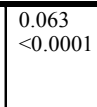 \\
\hline $\mathrm{R}=0.580, \mathrm{R}^{2}=$ & $\begin{array}{l}0.323,5 \\
0.32 E=0.75\end{array}$ & $\frac{0.292}{p<<0.000}$ & & $\mathrm{R}=0.389, \mathrm{R}^{2}=0.131$ & SEE $=747$, & Ka.0001 & $R=0.654, R^{2}=1$ & $419, \mathrm{SEE}=\mathbf{0 . 7 6}$ & $\mid p<0.0001$ \\
\hline $\begin{array}{l}\text { LDL/HDL } \\
\text { ratio }\end{array}$ & 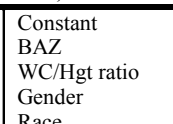 & $\begin{array}{l}-3.088 \\
-0.0988 \\
0.022 \\
0.130 \\
0.130\end{array}$ & 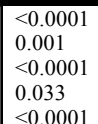 & \begin{tabular}{|l|} 
Constant \\
BAZ \\
WC/Hgt ratio
\end{tabular} & $\begin{array}{l}\begin{array}{l}0.010 \\
0.001 \\
<0.0001\end{array} \\
<0\end{array}$ & & $\begin{array}{l}\text { Constant } \\
\text { WC/Hgt ratio }\end{array}$ & \begin{tabular}{|l|}
-1.958 \\
0.628
\end{tabular} & \begin{tabular}{|l|l}
$\begin{array}{l}0.004 \\
<0.0001\end{array}$ \\
$<.001$
\end{tabular} \\
\hline
\end{tabular}

In both races the prevalence of abnormal lipid values were high but gender seemed to affect TC, Trig, LDL-C, TC/HDL ratio and LDL/HDL ratio in both races. The most common form of dyslipidemia found in the current study was low HDL-C a finding previously reported in adolescents ${ }^{18}$. These values are however comparable with what has been reported in othe developing countries worldwide ${ }^{13,19}$.

Hypercholesterolemia and elevated concentrations of LDL-C in adolescents have been linked to genetic susceptibility. It is a well-known finding that family history and low birth weight contribute to the pathogenesis of $\mathrm{CVD}^{7,20}$. These findings support the hypothesis of fetal origins of cardiovascular and metabolic diseases in later life ${ }^{21}$. Young people with a family history of high blood pressure and Type 2 diabetes, irrespective of their adipocity had significantly higher insulin and abnormal lipid levels ${ }^{20}$, and tended to have greater fat mass. However, elevated TC has been found in adolescents with and without familial history of premature CVD events

Unfortunately in the current study family history of CVD in the studied adolescents was not recorded as this could have added valuable information on the observed phenomenon. In order to avoid over speculation it is necessary to keep in mind that a number of interrelated factors are often associated with and may contribute to the development of dyslipidemia in adolescents ${ }^{20}$. But on the other hand it has been previously reported that in South Africa the prevalence of CVDs is increasing at an alarming rate in all races ${ }^{23,24}$. This has been partly linked to the nutrition transition the country is undergoing ${ }^{25}$ with a shift to a more westernised lifestyle including fatty food and an increase in the intake of fast foods by the South African population ${ }^{26}$.

It is known that diet is modulated by several effects and it has been established that it is an important determinant of plasma lipids. Serum TC levels have been found to correlate with cholesterol and saturated fat intake ${ }^{27}$ On the other hand replacement of fat by carbohydrates in the diet results in significant reduction of HDL-C concentrations $^{28}$. This could be a possible explanation for the observed increase in low HDL-C levels especially in blacks who even though undergoing the nutrition transition their diet is still largely made up of car- On the other hand, the use of other indices such as

bohydrates. Unsurprisingly the same has been reported skinfold thickness still need further research with larger
Evidence shows that elevated TC and LDL-C levels increase the risk of CVD. Others have also revealed that low HDL-C levels are independent risk factors for atherosclerotic vascular disease ${ }^{30}$. It has been reported that individuals with low HDL-C have an abnormal HDL sub-class distribution, with lower levels of large particles and increased levels of small HDL ${ }^{31}$. This abnormality in HDL sub-populations is associated with CHD prevalence ${ }^{32}$ and increased recurrence of coronary events $\mathrm{s}^{33}$. Though the above associations have atherosclerosis begin to manifest itself early in life and its initial stages are associated with adverse lipid profiles in children and adolescents ${ }^{11,12}$. Thus the above can be seen as suggesting that the abnormalities found in the current study's adolescents may predispose them to increased coronary heart disease risk later in life.

Elevated TC levels in childhood have been shown to track into adulthood ${ }^{3,11,34}$, a phenomenon observed also with measures of adiposity especially BMI ${ }^{34}$. Moreover previous researchers have reported that when there is risk factor clustering in adolescence as observed in the current study (results not shown),these adolescents are at an increased risk of developing CVDs in adulthood

In both races TC, Trig, LDL, TC/HDL ratio and LDL/ HDL ratio were positively associated with both BAZ and $\mathrm{WC} / \mathrm{Hgt}$ ratio. HDL on the other hand was inversely associated with BAZ and WC/Hgt ratio as well as WC. These findings are congruent with what has been found by Lima et al ${ }^{13}$. The association between adipocity and abnormal lipid levels have long been established ${ }^{35}$, with longitudinal changes in relative weight being associated with changes in these risk factors ${ }^{36}$. In addition these findings are supplemented by the observation that linear regression models revealed $\mathrm{WC} / \mathrm{Hgt}$ ratio as the most predominant factor predicting most measured lipid parameters. This opens a new window for research into the use of anthropometric indices as surrogate measures to screen for dyslipidemia among other conditions, an area that still requires further research. been reported in adults only, recent evidence show that 

public health implication and reduce the risks associated with dyslipidemia if it can be detected early in adolescence especially in individuals with a familial history of dyslipidemia. Thus the current results show that even at this early stage abdominal fat deposition contribute to an adverse lipid profile ${ }^{18}$.

Studies have linked the association between hypertriglyceridemia and central obesity to the increased number and size of adipocytes in the abdominal region, which promote insulin resistance and thus intensifying the release of free fatty acids (FFA) into the circulation. The FFA then provide a substrate for triacylglycerol synthesis in the liver, leading to increased hepatic release of Trig rich very low density lipoprotein particles into the circulation ${ }^{37}$.

Hyperinsulinaemia is also known to enhance hepatic VLDL synthesis, thus it may directly contribute to the increased plasma Trig and LDL-C levels ${ }^{38}$. Resistance to the action of insulin on lipoprotein lipase in peripheral tissues may also contribute to elevated Trig and LDL- C (39). It has also been suggested that insulin resistance may be involved in the reduced HDL-C levels in type 2 diabetes patients. As such the findings in the present study suggest the need to monitor lipid levels in adolescents.

Gender and pubertal development stage are the other factors that have been shown to influence the lipid profile of individuals ${ }^{14}$, while other evidence has shown that BMI influences Trig levels irrespective of age and gen$\operatorname{der}^{18}$. However, in the current study no data was available on the adolescents' pubertal development stages to can assist in adding to this pool of literature. On the contrary adjusting for gender affected the association between lipid parameters and measures of adiposity supporting the earlier findings that gender does play a role in the adolescents' lipid profile exhibited probably due to differences in hormonal changes ${ }^{14}$.

Though it has been shown that, most risk factors do track into adulthood; substantial proportions of young people with high risk levels had no risk levels in adult$\operatorname{hood}^{40}$. These discrepancies have been associated with changes in lifestyle habits ${ }^{40}$, suggesting that modifiable risk factors in the time between adolescence and adult hood have the potential to shift adolescents with high risk lipid levels into adults with low-risk levels and vice vers $^{40}$. These modifiable risk factors include adipocity, smoking, hormonal contraceptive use ${ }^{40}$, physical tivity ${ }^{41}$, upwards social mobility from lower sociodoption of a healthier $\operatorname{diet}^{40}$. The above findings show that all is not lost in young children as interventions to change the modifiable risk factors can aid in reducing the adverse effects of impaired lipid tracking from adolescence by reversing them.

\section{Conclusion}

The study showed that whites exhibited more associations between dyslipidemia and anthropometric indicators as compared to black adolescents with $\mathrm{WC} / \mathrm{Hot} \mathrm{ra}-$ tio being the index associated with most measured lipid parameters, suggesting that there might be differences in the lipid metabolism or even susceptibility to risk factors in adolescents. Furthermore, the association between dyslipidemia and adipocity in this study adds to the current literature that it is necessary to introduce screening and preventative measures at an early age due to the adverse consequences posed by tracking of these risk factors into adulthood, but these results have to be cautiously interpreted as the smaller sample sizes in both populations might have affected the results in one way or another as such warranting larger epidemiological studies in this setting.

\section{Acknowledgements}

The cooperation of the District Office of the Department of Education, school authorities, teachers, patents and children in the Tlokwe Municipality is greatly appreciated. We thank the fourth year $(2010,2011$ honours groups) students in the School of Biokinetics, Recreation and Sport Science for their assistance in the collection of the data. In addition, the contribution of all researchers in the PAHL study is highly appreciated. This material is based upon work supported financially by the National Research Foundation (NRF) and Medical Research Council of South Africa (MRC).

\section{References}

. McGill HC, McMahan CA, Herderick EE, Malcom GT, Tracy RE, Strong JP. Origen of atherosclerosis in childhood and adolescence. American Journal of Clinical Nutrition 2000; 72 (5 Suppl.): 1307S-1315S.

2. Kavey RE, Daniels SR, Lauer RM, Atkins DL, Hayman LL, Taubert K. American Heart Association guidelines for primary prevention of atherosclerotic cardiovascular disease beginning in childhood. Circulation 2003; 107: 1562-1566.

3. Webber LS, Srinivasan SR, Wattigney WA, Berenson
GS. Tracking of serum lipids and lipoproteins from childhood to adulthood: the Bogalusa Heart Study. American Journal of Epidemiology 1991; 133: 884-899.

4. Kotronen A, Yki-Järvinen $\mathrm{H}$, Sevastianova K, et al. Comparison of the relative contributions of intra-abdominal and liver fat to components of the metabolic syndrome. Obesity 2011; 19(1):23-28,

5. Wang Y, Lobstein T. Worldwide trends in childhood overweight and obesity. International Journal of Pediatric Obesity 2006; 1: 11-25.

6. Baker JL, Olsen LW, S.rensen TI. Childhood bodymass index and the risk of coronary heart disease in adulthood. New England Journal of Medicine 2007; 357 2329-2337.

7. Ruderman N, Chisholm D, Pi-Sunyer X, Schneider S. The metabolically obese, normal-weight individual revisited. Diabetes 1998; 47: 699e-713e.

8. Dvorak RV, DeNino WF, Ades PA, Poehlman ET. Phenotypic characteristics associated with insulin resistance in metabolicallyobese but normal-weight young women. Diabetes 1999;48:2210e-2214e.

9. Skyler JS, Oddo C. Diabetes trends in the U S A. Diabetes Metabolism Research Review 2002; (18: Suppl 3): S21-S26.

10. Gregg EW, Cheng YJ, Cadwell BL, et al. Secular trends in cardiovascular disease risk factors according to body mass index in US adults. Journal of American Medical Association 2005;293: 1868- 1874.

11. Berenson GS, Srinivisan SR, Bao W, Newman WP, Tracy RE, Wattingney WA. Association between multiple cardiovascular risk factors and atherosclerosis in children and young adults. New England Journal of Medicine 1998; 338 (23): 1650-1656.

12. Raitakari OT, Juonala M, Kahonen M, et al Cardiovascular risk factors in childhood and carotid artery intima-media thickness in adulthood: the Cardiovascula Risk in Young Finns Study. Journal of American Medical Association 2003; 290: 2277-2283.

13. Lima SCVH, Lyra COL, Pinheiro LGB, de Azevedo PRM, Arrais RF, Pedrosa LFC. Assoication between dyslipidemia and anthropometric indicators in adolescents. Nutrition Hospital; 2011; 26: 304-310.

14. Berenson GS, Srinivasan SR, Cresanta JL, Foster TA, Webber LS.Dynamic changes of serum lipoproteins in children during adolescence and sexual maturation. American Journal of Epidemiology 1981; 113 (2): 157170.

15. Reddy SP, Resnicow K, James S, et al. Rapid increases in overweight and obesity among South African adolescents: comparison of data from the South African National Youth Risk Behaviour Survey in 2002
2008. American Journal of Public Health 2012; 102 (2): . 268

Marfell-Jones M, Olds T, Stewart A, Lindsay Carte JE. 2006. International Standards for Anthropometry Assessment. (2nded.) The International Society for the Advancement of Kinanthropometry. 137.

de Onis M, Onyango AW, Borghi E, Siyam A, Nishida C, Siekmann J. 2007. Development of a WHO growth reference for school-aged children and adolescents. Bulletin of the World Health Organization;85 (9): 660-667.

18. Posadas-Sanchez R, Posadas-Romero C, ZamoraGonzalez J, Mendonza-Perez E, Cardoso- Saldaña G Yamamoto-Kimura L. Lipid and lipoprotein profiles and prevalence of dyslipidemia in mexican adolescents. Metabolism 2007; 56 (12): 1666-1672.

19. Vieira ACR, Alvarez MM,Kanaan S, Sichieri R, Veiga GV. Body mass índex predicting hyperglycemia and serum lipid changes in Brazilian adolescents. Review Saúde Pública 2009; 43 (1): 44-52.

20. Guerrero-Romero F, Rodri'guez-Mora'n F. Prevalence of dyslipidemia in non-obese prepubertal chilren and its association with family history of diabetes, high blood pressure, and obesity. Archives of Medical research 2006; 37: 1015-1021.

21. Thornburg KL.Fetal origins of cardiovascular disease. Neonatal Reviews 2004;5: e527-e533.

22. Romaldini CC, Issler H, Cardoso AL, Diament J, Forti N. Risk factors for atherosclerosis in children and adolescents with family history of premature coronary artery disease. The Journal of Pediatrics 2004; 80:135-140. 23. Alberts M, Urdal P, Steyn K, et al. Prevalence of cardiovascular diseases and associated risk factors in a rural black population of South Africa. European Jour nal of Cardiovascular Prevetive Rehabiliation 2005; 12(4): $347-354$

24. Ikem I, Sumpio BE. Cardiovascular disease: the new epidemic in sub-Saharan Africa. Vascular 2011; 19(6): 301-307

5. Vorster HH, Bourne LT, Venter CS, Oosthuizen W. Contribution of nutrition to the health transition in developing countries: a framework for research and intervention. Nutrition Review 1999; 57(11): 341-349.

26. Steyn NP, Labadarios D, Nel JH. Factors which influence the consumption of street foods and fast foods in South Africa--a national survey. Nutrition Journal 2011; 10: 104

27. Nicklas TA, Farris RP, Smoak CG, et al. Dietary actors relate to cardiovascular risk factors in early life. Bogalusa Heart Study. Arteriosclerosis Thrombosisand Vascular Biology 1988; 8:193-199. 
28. Merchant AT, Anand SS, Kelemen LE, et al. Carbohydrate intake and HDL in a multiethnic population. American Journal of Clinical Nutrition 2007; 85: 225-230.

29. Knuiman JT, West CE, Katan MB, Hautvast JG. Total cholesterol and high density lipoprotein cholesterol levels in populations differing in fat and carbohydrate intake. Arteriosclerosis Thrombosis and Vascular Biology 1987; 7: 612-619.

30. Assmann G, Schulte H. Role of triglycerides in coronary artery disease: lessons from the Prospective Cardiovascular Munster Study. American Journal of Cardiology 1992; 70: 10H-13H.

31. Asztalos BF, LefevreM, Foster TA, et al. Normolipidemic subjects with low HDL cholesterol levels have altered HDL subpopulations. Arteriosclerosis Thrombosis and Vascular Biology 1997; 17: 1885-1893. 32. Asztalos BF, Cupples LA, Demissie S, et al. Highdensity lipoprotein subpopulation profile and coronary heart disease prevalence in male participants of the Framingham Offspring Study. Arteriosclerosis Thrombosis and Vascular Biology 2004; 24: 2181-2187.

33. Asztalos BF, Collins D, Cupples LA, et al., Value of high-density lipoprotein (HDL) subpopulations in predicting recurrent cardiovascular events in the Veterans Affairs HDL Intervention Trial. Arteriosclerosis Thrombosis and Vascular Biology 2005; 25: 2185-2191. 34. Juhola J, MagnussenCG, Viikari JSA, et al., Tracking of serum lipid levels, Blood Pressure, and Body Mass Index from childhood to Adulthood: The Cardiovascular Risk in Young Finns Study. Journal of Pediatrics 2011; 159: 584-590.
35. Williams DP, Going SB, Lohman TG, Harsha DW, Srinivasan SR, Webber LS. Body fatness and risk for elevated blood pressure, total cholesterol and serum lipoprotein ratios in children and adolescents. American Journal of Public Health 1992; 82: 358-363.

36. Freedman DS, Burke GL, Harsha DW,Srinivasan SR, CresantaJL,Webber LS. Relationship of changes in obesity to serum lipid and lipoprotein changes in childhood and adolescence. Journal of American Medical Association 1985 ; 254: 515-520.

37. Steinberger J, Daniels SR. Obesity, insulin resistance, diabetes and cardiovascular risk in children. Circulation 2003; 107: 1448-1464.

38. Stalder MP, Metta D, Suenram A. Relationship between plasma insulin levels and high- density lipoprotein cholesterol levels in healthy men. Diabetologia1981; 21:544-548.

39. Sadur CN, Yost TJ, Eckel RH. Insulin responsiveness of adipose tissue lipoprotein lipase is delayed but preserved in obesity. Journal of Clinical Endocrinology and Metabolism 1984; 59:1176-1182.

40. Magnussen CG, Thomson R, Cleland VJ, Ukoumunne OC, Dwyer T, Venn A. Factors affecting the stability of blood lipid and lipoprotein levels from youth to adulthood: Evidence from the Childhood Determinants of Adult Health Study. Archives of Pediatric Adolescent Medicine 2011; 165 (1):68-76.

41. Leon AS, Sanchez OA. Response of blood lipids to exercise training alone orcombined with dietary intervention. Medicine Science and Sports Exercise 2001; 33(6) (suppl): S502-S515, S528-S529. 